\title{
NEOPLASIAS ASTROCITÁRIAS E CORRELAÇÃO COM AS PROTEÍNAS P53 MUTADA E Ki-67
}

\author{
Gustavo Rassier Isolan', Jurandir Marcondes Ribas Filho², \\ Paola Maria B.S. Isolan ${ }^{3}$, Allan Giovanini4, Osvaldo Malafaia5, \\ L.I. Dini' ${ }^{6}$, Arthur Kummer Jr. ${ }^{7}$, Alexandre W. Negrão ${ }^{8}$
}

\begin{abstract}
RESUMO - As neoplasias astrocitárias correspondem a 60\% dos tumores do sistema nervoso central, sendo o estudo da biologia molecular um importante passo para a compreensão da gênese e comportamento biológico destas doenças. As proteínas Ki-67, que é um marcador de proliferação celular, e p53, que é o produto do gene supressor de tumor de mesmo nome, são importantes marcadores tumorais. $O$ objetivo deste estudo foi identificar e quantificar as proteínas Ki-67 e produto do gene supressor de tumor TP53 em diferentes graus de malignidade das neoplasias astrocitárias, bem como analisar suas relações com idade e sexo. Foram estudadas por imunohistoquímica as proteínas Ki-67 e p53 em 47 pacientes com neoplasias astrocitárias ressecadas cirurgicamente, classificadas previamente e revisadas quanto ao grau de malignidade, de acordo com o proposto pela Organização Mundial da Saúde. Os núcleos celulares imunomarcados foram quantificados no programa Imagelab-softium pela razão paramétrica absoluta entre os núcleos de células positivas e o número total de células tumorais, sendo contadas 1000 células. 0 delineamento utilizado foi transversal não controlado. Para análise estatística as variáveis foram divididas em grupos, que para a Ki-67 foram ausente, $<5 \%$ e $>5 \%$ e para a 553 foram ausente (0), $<25 \%(1+)$, entre 25 e $50 \%(2+)$, entre 50 e $75 \%$ (3+) e maior que $75 \%(4+)$. Ki-67 esteve presente em 37 casos $(78,72 \%)$ expressando correlação com maior grau de malignidade $(p<0,001)$. A p53 esteve presente em 14 casos $(35,13 \%)$ tendo maior correlação com astrocitoma grau IV $(p=0,59)$. Não houve correlação estatisticamente significativa entre p53 e Ki-67, bem com entre estas variáveis, idade e sexo. Concluiu-se que a hipótese de maior presença de Ki-67 e p53 em neoplasias astrocitárias de maior grau de malignidade, com exceção da correlação entre grau III e p53, é corroborada pelos resultados deste estudo.
\end{abstract}

PALAVRAS-CHAVE: astrocitoma, p53, Ki-67.

\section{Astrocytic neoplasms and correlation with mutate p53 and Ki-67 proteins}

\begin{abstract}
The astrocytic neoplasms respond by $60 \%$ of the central nervous system tumors, being the study of the molecular biology an important step for the understanding of the genesis and biological behavior of these diseases. The Ki-67 proteins, which are markers of the cellular proliferation, and p53, which is the product of the tumor suppressor gene TP53, are both important tumoral markers. This study intends to identify and quantify the Ki-67 and p53 proteins in astrocytic tumors of diffe rent grades of malignancy, as well as to analyze their relations with age and gender. Ki-67 and p53 proteins in 47 patients with surgic ally resected astrocytic neoplasms were studied through immunohistoc hemistry. They have been previously classified and reviewed conceming their histological grade, as suggested by the World Health Organization. The immunomarked cellular nuclei were quantified by the program Imagelab-softium for the absolute parametric reason between the nuclei of the positive cells and the total amount of tumoral cells, being counted 1000 cells. The lineation used has been transversal not controlled. For the statistical analysis the variables were divided into groups. For the Ki-67 they were absent, $<5 \%$ and $>5 \%$ and for p53 they were absent $(0),<25 \%(1+)$, between 25 and $50 \%(2+)$, between 50 and $75 \%(3+)$, and higher than $75 \%(4+)$. Ki-67 was present in 37 cases (78.72\%) evidencing a correlation with a higher malignancy degree $(p<0,001)$. p53 was present in 14 cases $(35.13 \%)$ with a higher correlation with as trocytoma grade IV ( $p=0.59)$. There has not been a statistically significant correlation between $\mathrm{p} 53$ and Ki-67, as well as among these variables, age and gender. The hypotheses of a greater presence of Ki-67 and p53 in astrocytic neoplasms with a higher degree of malignancy, except for the correlation between grade III and p53, is corroborated by the results of this study.
\end{abstract}

KEY WORDS: astrocytoma, p53, Ki-67.

\begin{abstract}
Pós-graduação do Instituto de Pesquisas Médicas do Paraná (IPEM) em Princípios da Cirurgia e da Universidade Federal do Paraná (UFPR) em Clínica Cirúrgica, Faculdade Evangélica do Paraná (FEPAR), Hospital Universitário Evangélico de Curitiba (HUEC) e Centro Universitário Positivo (UNICENP), Curitiba PR, Brasil: ${ }^{1}$ Neurocirurgião, Mestre em Princípios da Ciru rgia pelo IPEM, Doutor em Clínica Cirúrgica pela UFPR; ${ }^{2} \mathrm{C}$ iru rgião. Doutor em Clínica Cirúrgica pela UFPR, Professor titular de ciru rgia da FEPAR; ${ }^{3} \mathrm{Ci}$ ru rgiã pediatra, mestranda em Clínica Cirúrgia pela UFPR; ${ }^{4}$ Doutor em Patologia Bucal (Universidade de São Paulo), coordenador do Laboratório de Imuno-histoquímica da UNICENP; ${ }^{5}$ Coordenador da Pós-Graduação do IPEM em Princípios da Cirurgia; ${ }^{6}$ Neurocirurgião; ${ }^{7} \mathrm{Chefe}$ do Departamento de Neurocirurgia do HUEC; ${ }^{8}$ Neurocirurgião, Mestrando em Princípios da Cirurgia pelo IPEM
\end{abstract}

Recebido 5 Abril 2005, recebido na forma final 22 Junho 2005 Aceito 12 Agosto 2005.

Dr. Gustavo Rassier Isolan - Rua Ramiro Barcelos 2171/31 - 90035-007 Porto Alegre RS - Brasil. E-mail: gisolan@yahoo.com.br 
As neoplasias astrocitárias correspondem a $60 \%$ dos tumores do sistema nervoso central (SNC), sendo o estudo da biologia molecular um importante passo para a compreensão da gênese e comportamento biológico destas doenças ${ }^{1,2}$. As proteínas Ki-67, que é um marcador de proliferação celular, e o produto do gene supressor de tumor TP53, que é um regulador da transcrição induzida por dano ao DNA, são importantes marca dores tumorais. $O$ grau em que uma célula se prolifera tem forte correlação nas neoplasias com a intensidade da carcinogênese. Dessa maneira, o estudo de marcad o res de proliferação celular torna-se importante coadjuvante na pesquisa do câncer. Em relação aos marca d ores de proliferação celular, o antígeno Ki67 é considerado, atualmente, o de maior acurácia, sendo analisado em diversos tipos de neoplasias, dentre estas as do SNC. Identifica-se a presença deste antígeno em tumores emblocados em parafina mediante reação do antígeno com o anticorpo MIB-1.

A etiologia dos astrocitomas é desconhecida. Todavia, fatores genéticos hereditários, como sínd rome de Turcot, doença de Ollier, síndrome de Mafucci, ou mesmo fatores externos como a radiação ionizante são responsáveis por casos esporádicos. Corroborando estas observações, tem sido relacionada a mutação genética como fator principal e desencadeante das neoplasias astrocitárias, dentreas quais a do gene supressor de tumor TP53 , o qual sintetiza uma proteína de mesmo nome que tem importância fundamental na regulação do ciclo celular e apoptose, mas que, quando mutada, está associada a diversos graus de comportamento neoplásico. A indução da parada do ciclo celular pela via p53 depende da habilidade de esta se comportar como verdadeiroativador de transativação de seqüência específica ${ }^{3}$. O produto de vários genes com função de estacionar o ciclo celular pode ser induzido pela p53. Os principais são as p roteínas p21, MDM2 e Gadd45. Enquanto a ativação de transativação parece ser essencial para a indução da parada do ciclo celular, sua função, no que diz respeito à apoptose, é controversa. Tem sido relatado que a p53 pode induzir apoptose através de vias dependentes e independentes da transativação ${ }^{3}$. Dentre os mediadores da via apoptótica induzidos pela p53, estão o gene bax, o qual acelera a apoptose através da ativação de caspases que alteram a estrutura da mitocôndria e a Fas/APO1, da família de receptores do fator de necrose tumoral, que promove transdução de sinal ao se ligar à proteína DR5, resultando na indução da cascata de caspases que levam à apoptose ${ }^{4}$. Uma terceira via para apoptose é mediada pela IGFBP-3, antagonista do IGF-1, que bloqueia a sinalização do fator de crescimento mitogênico ${ }^{5}$.

Este estudo estabeleceu a presença das proteínas Ki-67 e p53 mediante a técnica de imuno-histoquímica em 47 neoplasias astrocitárias de diferentes graus histológicos, sendo o objetivo correlacionar as seguintes variáveis: 1 . Ki-67 com grau de malignidade; 2 . p53 com grau de malignidade; 3. p53 com Ki-67; 4 . Ki-67 e p53 com idade e sexo.

\section{MÉTODO}

O estudo foi realizado no Instituto de Pesquisas Médicas (IPEM) e no Laboratório de Imuno-histoquímica do Centro Universitário Positivo (UNICENP), na cidade de Curitiba, após ter sido aprovado pelo comitê de ética . As amostras foram analisadas quanto as suas variáveis de grau histológico, idade e sexo.

O estudo foi retrospectivo com delineamento tipo transversal não controlado.

A amostra consistiu de 47 blocos de parafina contendo neoplasias astrocitárias. Estes tumores eram provenientes de pacientes tratados no Serviço de Neurocirurgia do HUEC entre 1997 e 2001. Cada amostra foi submetida a avaliação histológica prévia para inclusão no estudo, sendo a seguir analisada e graduada de acordo com a classificação da OMS (2000). Todos os tumores estavam identificados e processados de acordo com técnicas histológicas de rotina, conservados em solução de formol e tamponados e fixados em parafina.

Cada caso teve o bloco histológico selecionado para imuno-histoquímica e foi reavaliado independentemente por dois patologistas para se obter a confirmação do laudo histológico efetuado previamente, seguindo os critérios p ropostos pela OMS (2000). Os tumores foram distribuídos da seguinte forma: quatro tumores eram grau I (8, $5 \%), 12$ eram grau II (25,5\%), cinco eram grau III $(10,6 \%)$ e 26 eram grau IV (55,3\%).

A imunoexpressão das proteínas Ki-67 e p53 foi obtida através do método imunoenzimático da streptoavidina-biotina-peroxidase. A recuperação antigênica foi realizada com os cortes sendo submetidos à solução de ácido cítrico na concentração de 0,01M e pH 6,0 em microondas em três vezes de cinco minutos cada. Após passagem por água destilada executou-se o bloqueio da peroxidase endógena com solução de peróxido de hid rogênio a 3\%. Para que não ocorressem alterações significativas de $\mathrm{pH}$, os cortes foram submetidos a rápida incubação em solução tampão na concentração de 0,05M e pH 7,4. Utilizaram-se os anticorpos primários contra o Ki-67 (MIB-1, DAKO, diluição de 1:500) e a p53 (clone DO-7 ${ }^{\circledR}, \mathrm{DAKO} / \mathrm{AS}$, diluição de 1:50), durante 18 horas (over night) a $4^{\circ} \mathrm{C}$ em câmara úmida na solução tampão acrescido de albumina bovina a $1 \%$ contendo azida sódica (Azida Sódica ${ }^{\circledR}$, Biotest S/A, São Paulo, Brasil). Para re- 
Tabela 1. Variáveis estudadas e medidas descritivas

\begin{tabular}{lc}
\hline Variável & Medida Descritiva \\
\hline Idade & $46 \pm 18^{1}$ \\
Gênero & \\
Feminino & $24(51 \%)$ \\
Masculino & $23(49 \%)$ \\
Grau & \\
I & $4(8 \%)$ \\
II & $12(25 \%)$ \\
III & $5(11 \%)$ \\
IV & $26(55 \%)$ \\
Ki-67 & $9(2 \text { a } 31)^{2}$ \\
p53 & $0(0 \text { a } 1)^{2}$ \\
\hline n=47 (1) Média com desvio padrão; (2) Mediana (intervalo interquartil).
\end{tabular}

Tabela 2. Comparação das variáveis, através do teste de Wilco xon-Mann-Whitney, entre os pacientes com p53 e sem p53.

\begin{tabular}{lccc}
\hline Parâmetro & $\begin{array}{c}\text { p53 presente } \\
n=13\end{array}$ & $\begin{array}{c}\text { p53 ausente } \\
n=34\end{array}$ & Valor- $P$ \\
\hline Grau & $4(2 \text { a } 4)^{1}$ & $4(2$ a 4$)$ & 0,94 \\
Ki-67 & $8,5(1,5 \text { a } 43)^{1}$ & $12(1,5 a 27)$ & 0,65 \\
Idade & $45 \pm 20^{2}$ & $48 \pm 12$ & 0,43 \\
\hline
\end{tabular}

(1) med (IQ): mediana e intervalo interquartil (percentil 25 a percentil 75); (2) média com desvio padrão.

Tabela 3. Comparação das variáveis, através do teste de Wilco xon-Mann-Whitney, entre os pacientes com ki-67 e sem ki-67.

\begin{tabular}{lccc} 
Parâmetro & Ki-67 presente & Ki-67 ausente & Valor- $P$ \\
$\mathrm{n}=37$ & $\mathrm{n}=10$ & \\
\hline Grau & $2(1 \mathrm{a} 3)^{1}$ & $4(2,5$ a 4$)$ & 0,36 \\
p53 & $0(0 \text { a } 0,7)^{1}$ & $0(0$ a 1$)$ & 0,18 \\
Idade & $39(18 \text { a } 72)^{2}$ & $48(34$ a 58$)$ & 0,90 \\
\hline
\end{tabular}

Med (IQ): mediana e intervalo interquartil (percentil25 a percentil75); (2) Média com desvio padrão.

velar a reação antígeno-anticorpo as lâminas foram incubadas em $300 \mathrm{mg}$ do cormógeno 3,3-diaminobenzidina (Diaminobenzidina ${ }^{\circledR}$ Sigma Chemical, St. Louis, USA). Foram selecionados cortes histológicos para o estudo imuno-histoquímico a partir de preparações coradas pela $\mathrm{H} / \mathrm{E}$, rep resentativos da neoplasia e sem artefatos técnicos. Cortes com extensas áreas de necrose foram descartados devido a possíveis viéses de aferição na avaliação imuno-histoquímica.

A análise das células imunopositivas para os anticorpos contra p53 e Ki-67 foi realizada com duas repetições em campos definidos e escolhidos aleatoriamente, sendo consideradas positivas somente marcações em núcleos, de coloração castanha, independente da intensidade da coloração, somente com suficiência para diferenciação entre positivo e negativo. Os controles positivos foram casos de câncer mamário com intensa imu-

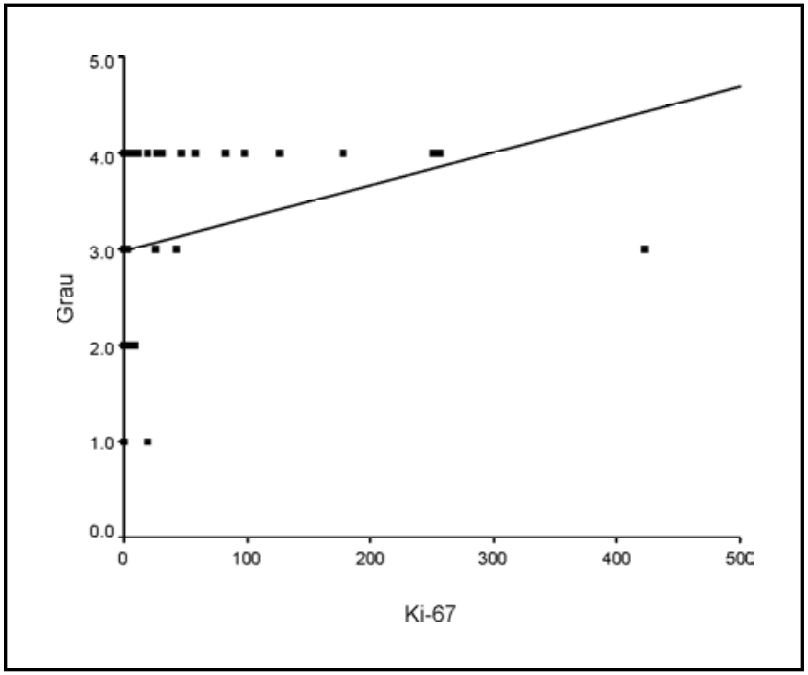

Gráfico 1. Correlação linear entre ki-67 e grau histológico $P<$ 0,001 . No eixo horizontal. Ki-67 corresponde ao número de cé lulas imunomarcadas, enquanto no eixo vertical 1,2,3 e 4 cor respondem, respectivamente, aos graus I, II, III e IV.

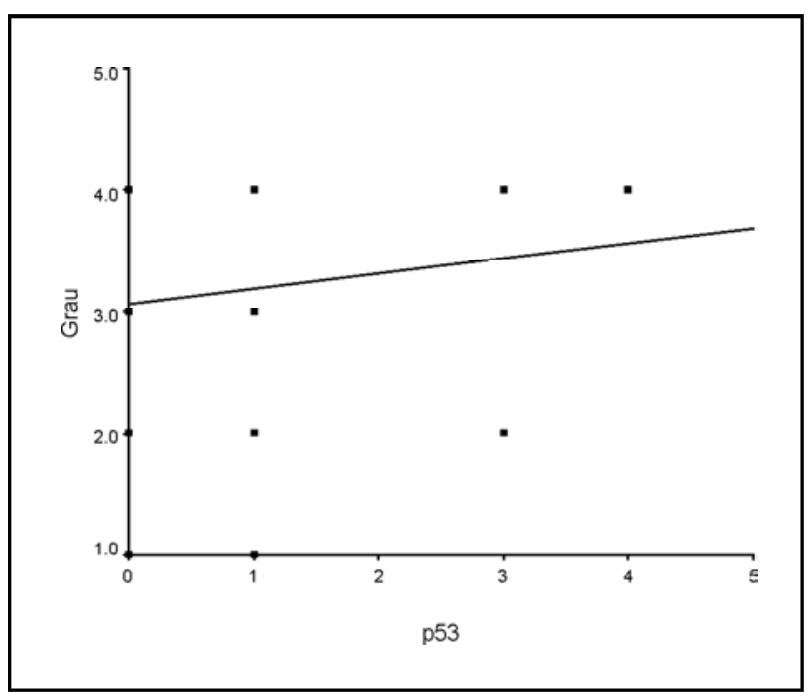

Gráfico 2. Correlação linear entre $p 53$ e grau histológico $P=$ 0,59 . No eixo horizontal p53 0,1,2,3 e 4 correspondem, respec tivamente a $0,1+, 2+, 3+$ e 4+, enquanto no eixo vertical 1,2,3 e 4 correspondem, respectivamente, aos graus I, II, III e IV.

nomarcação para ambos os antígenos. As imagens de cada campo foram obtidas em microscópio óptico, em campos com aumentos de 400 vezes, sendo transferidas para um monitor acoplado a um sistema computadorizado, onde foram quantificados os núcleos que expressavam imunomarcação após sua individualização pelo software Imagelab-Softium. A imunorreatividade foi dividida conforme o número de células imunomarcadas em um total de 1000 células contadas em campos com aumentos de 400 vezes. Em relação ao Ki-67, a quantificação gerou um índice de marcação que foi obtido com a razão paramétrica absoluta entre os núcleos de células positivas e o número total de células tumorais contadas, 


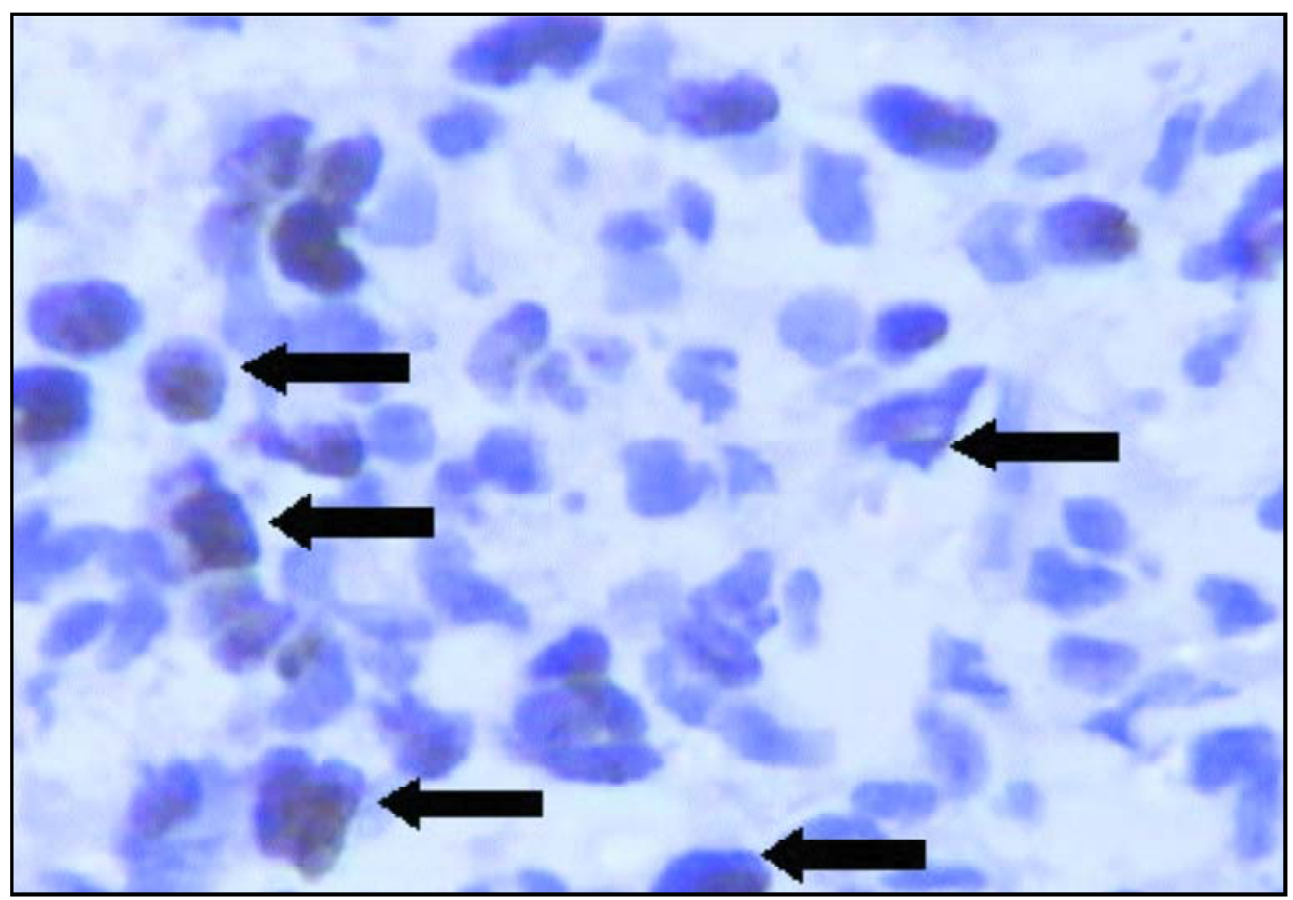

Fig 1. Ki-67 em neoplasia astrocitária grau IV (aumento de 400X). As setas indicam núcleos imunoreativos para o antígeno Ki-67.

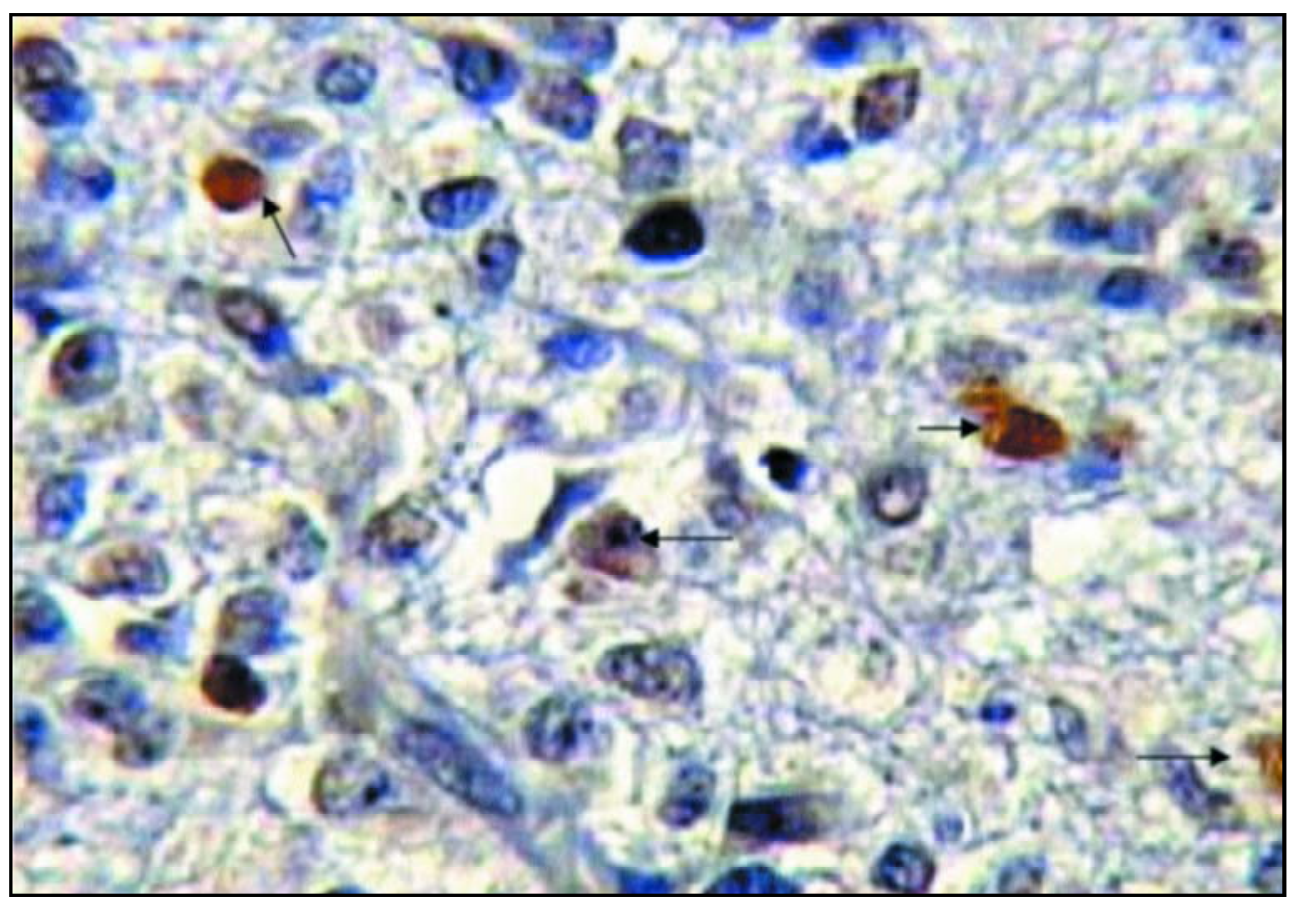

Fig 2. p53 em neoplasia astrocitária grau IV (400X). Observam-se núcleos de coloração castanha (setas) indicando a p53 mutada.

sendo estabelecidos três grupos, que foram 1. ausência de células marcadas, 2 . menos de $5 \%$ das células marcadas e 3. mais de $5 \%$ das células marcadas ${ }^{6}$. Quanto à avaliação da p53, a quantificação gerou um índice de marcação que foi obtido com a razão paramétrica absoluta entre os núcleos de células positivas e o número total de células tumorais, sendo aplicado o seguinte esque- ma: 0, sem marcação; $1+$, marcação em menos de $25 \%$ das células tumorais; $2+$, marcação entre 25 e $50 \%$ das células tumorais; 3+, marcação entre 50 e $75 \%$ das células tumorais e $4+$, marcação em mais de $75 \%$ das células tumorais?.

O coeficiente de correlação de Spearman foi utilizado para o estudo das correlações entre duas variáveis con- 
Quadro 1. Resultado da distribuição geral dos dados com putados.

\begin{tabular}{|c|c|c|c|c|c|}
\hline Caso & Idade & Sexo & Grau & Ki-67 & p53 \\
\hline 1 & 62 & M & I & $19 / 1000$ & $1+$ \\
\hline 2 & 52 & $\mathrm{~F}$ & II & $5 / 1000$ & $1+$ \\
\hline 3 & 52 & $M$ & IV & $83 / 1000$ & $1+$ \\
\hline 4 & 50 & $\mathrm{~F}$ & IV & $82 / 1000$ & 0 \\
\hline 5 & 71 & $\mathrm{~F}$ & IV & $4 / 1000$ & 0 \\
\hline 6 & 51 & $M$ & IV & $12 / 1000$ & 0 \\
\hline 7 & 16 & $\mathrm{~F}$ & II & $8 / 1000$ & 0 \\
\hline 8 & 85 & $\mathrm{~F}$ & I & $0 / 1000$ & 0 \\
\hline 9 & 46 & M & IV & $12 / 1000$ & $1+$ \\
\hline 10 & 61 & $\mathrm{~F}$ & IV & $31 / 1000$ & 0 \\
\hline 11 & 20 & $\mathrm{~F}$ & IV & $312 / 1000$ & 0 \\
\hline 12 & 38 & M & II & $0 / 1000$ & $3+$ \\
\hline 13 & 78 & $M$ & II & 0/1000 & 0 \\
\hline 14 & 47 & $\mathrm{~F}$ & III & $272 / 1000$ & $1+$ \\
\hline 15 & 8 & M & 1 & $0 / 1000$ & 0 \\
\hline 16 & 22 & $\mathrm{~F}$ & IV & 0/1000 & $3+$ \\
\hline 17 & 25 & M & II & $4 / 1000$ & 0 \\
\hline 18 & 21 & $\mathrm{~F}$ & IV & $126 / 1000$ & 0 \\
\hline 19 & 34 & $\mathrm{~F}$ & IV & $12 / 1000$ & 0 \\
\hline 20 & 45 & $M$ & IV & $178 / 1000$ & $3+$ \\
\hline 21 & 56 & M & IV & $27 / 1000$ & $1+$ \\
\hline 22 & 47 & M & IV & $111 / 1000$ & 0 \\
\hline 23 & 29 & $\mathrm{~F}$ & II & $5 / 1000$ & $1+$ \\
\hline 24 & 39 & $\mathrm{~F}$ & II & $9 / 1000$ & 0 \\
\hline 25 & 55 & M & IV & $12 / 1000$ & $1+$ \\
\hline 26 & 47 & $\mathrm{~F}$ & IV & $8 / 1000$ & 0 \\
\hline 27 & 26 & $\mathrm{~F}$ & III & $0 / 1000$ & 0 \\
\hline 28 & 45 & M & II & $2 / 1000$ & 0 \\
\hline 29 & 66 & $\mathrm{~F}$ & IV & $28 / 1000$ & $1+$ \\
\hline 30 & 63 & $\mathrm{~F}$ & IV & $0 / 1000$ & 0 \\
\hline 31 & 59 & M & IV & $256 / 1000$ & 0 \\
\hline 32 & 70 & $\mathrm{~F}$ & II & $0 / 1000$ & 0 \\
\hline 33 & 56 & $M$ & IV & $6 / 1000$ & 0 \\
\hline 34 & 27 & $\mathrm{~F}$ & IV & $87 / 1000$ & $1+$ \\
\hline 35 & 40 & M & II & $0 / 1000$ & 0 \\
\hline 36 & 57 & $\mathrm{~F}$ & IV & $46 / 1000$ & 0 \\
\hline 37 & 61 & M & II & $8 / 1000$ & 0 \\
\hline 38 & 62 & $M$ & IV & $98 / 1000$ & 0 \\
\hline 39 & 32 & $\mathrm{~F}$ & IV & $251 / 1000$ & 0 \\
\hline 40 & 58 & M & IV & $58 / 1000$ & 0 \\
\hline 41 & 27 & $\mathrm{~F}$ & III & $42 / 1000$ & 0 \\
\hline 42 & 58 & M & III & $423 / 1000$ & 0 \\
\hline 43 & 40 & $M$ & IV & $19 / 1000$ & 0 \\
\hline 44 & 34 & $\mathrm{~F}$ & II & $3 / 1000$ & 0 \\
\hline 45 & 48 & $M$ & IV & $177 / 1000$ & $4+$ \\
\hline 46 & 4 & $M$ & 1 & $0 / 1000$ & 0 \\
\hline 47 & 63 & $\mathrm{~F}$ & III & $26 / 1000$ & 0 \\
\hline
\end{tabular}

tínuas, correlacionando a variável grau com Ki-67, p53 e idade, bem como as variáveis Ki-67 e p53 entre si. O teste de Wilcoxon-Mann-Whitney foi utilizado para se testar a homogeneidade dos dois grupos (com e sem expressão de p53 e Ki-67) em relação às variáveis p53, ki-67, grau e idade. O teste de qui-quadrado foi utilizado para testar a homogeneidade dos dois grupos em relação ao sexo. A análise descritiva da idade foi realizada através da observação do cálculo de médias e desvios-padrão. Para a variável gênero foi calculada a freqüência absoluta.

\section{RESULTADOS}

Na Tabela 1 estão apresentadas as medidas descritivas das variáveis analisadas, através de suas medianas, acompanhadas pelos intervalos interquartil (percentil 25 a percentil 75), da média acompanhada do desvio-padrão, e da freqüência absoluta.

Quanto ao Ki-67, entre os casos positivos, 23 apresentaram menos de $5 \%$ e 15 tiveram este percentual maior de 5\%. Trinta e três casos, a maioria da amostra, foram negativos para a proteína p53 mutada. Dentre os casos positivos, o maior número (dez casos) estava no grupo com imunomarcação menor do que $25 \%$ das células tumorais (1+). Três casos evidenciaram imunomarcação entre 50 e $75 \%$ dos núcleos e em somente um esta esteve presente em mais de $75 \%$ dos núcleos examinados.

O grau histológico que teve maior correlação, tanto qualitativa quanto quantitativamente, com o antígeno Ki-67 foi o grau IV (Fig 1), enquanto que nos tumores de grau I esta correlação foi menor. Os dados estão expressos no Gráfico 1. O grau histológico que teve maior correlação com a presença da p53, qualitativamente e quantitativamente, foi o grau IV (34,6\%) (Fig 2), enquanto que o grau III foi o que apresentou a menor correlação, com $20 \%$ dos casos positivos (Gráfico 2). Não houve qualquer correlação significativamente estatística entre Ki67 e p53, bem como entre estas variáveis com idade e sexo (Tabelas 2 e 3).

A distribuição da amostra está apresentada no Quadro 1.

\section{DISCUSSÃO}

O antígeno Ki-67 está presente em todas as fases do ciclo celular com exceção de G0, sendo que sua identificação pela imunopositividade ao reagir com o anticorpo MIB-1 reflete a capacidade proliferativa do tumor ${ }^{8}$. O anticorpo MIB-1 para detecção do Ki-67 é o mais acurado quando comparada à identificação de outros antígenos ${ }^{8}$. A correlação entre grau histológico e Ki-67 foi estatisticamente significativa, tanto quando se dividiu a variável Ki67 em ausente e presente, como quando se dividiu em ausente, $<5 \%$ e $>5 \%$. Corroborando esse estudo, outros autores apresentaram resultados semeIhantes, sendo optada pela divisão $<5 \%$ e $>5 \%$ pelo fato desta apresentar correlação prognóstica ${ }^{9-12}$. 
A imunorreação da proteína Ki-67 nos pacientes com neoplasias grau II não foi em nenhum caso superior a $5 \%$ das células tumorais, justificando o fato de estes tumores não terem alto grau de proliferação celular, o que condiz com seu comport amento biológico mais benigno. No entanto, McKeever et al. ${ }^{10}$ demonstraram a importância da mensuração do Ki-67 ao dividir uma amostra de pacientes com astrocitomas grau II em índice de proliferação celular menor ou igual a 2\% ( 22 pacientes) e maior que $2 \%$ ( 28 pacientes). Utilizando o anticorpo MIB-1, estes autores verificaram pior prognóstico nos pacientes do segundo grupo.

O gene supressor de tumor p53 codifica uma proteína de mesmo nome, cuja ação reguladora sobre o ciclo celular dá-se por transcrição sobre a p21, que inibe o complexo CDK4/ciclina, impedindo a progressão da fase $\mathrm{G} 1$ para a fase $\mathrm{S}$ do ciclo celular. Além disso, esta proteína regula a apoptose das células que sofreram dano ao seu DNA ${ }^{1}$. Neste estudo, os tumores imunomarcados com p53 corre sponderam a $29,8 \%$ da amostra, sendo a maior parte correspondente ao grau IV, seguido pelos graus I e II e, por último, pelo grau III. Estudos prévios ${ }^{13,14}$ observaram resultados semelhantes em relação a essa distribuição, sugerindo que a inativação da p53 representa um evento genético precoce. Visto que uma parte dos tumores grau IV são oriundos da malignização de tumores de menor grau, a presença da p53 mutada nesses últimos indica que esta via molecular está envolvida no seu desencadeamento ${ }^{15}$. Com relação às neoplasias astrocitárias grau III, todavia, não há uma explicação alicerçada em hipóteses biológicas que justifiquem a menor presença da p53 mutada, devendo ser levado em conta que o pequeno número destes tumores na amostra estudada pode levar a um viés estatístico. Por outro lado, a porcentagem de tumores graus III e IV imunomarcados pela p53, no presente estudo, foi menor que estudos anteriores ${ }^{16-18}$.

Existem algumas explicações para esta discrepância. Inicialmente deve-se considerar o fato de que vários fatores estão envolvidos na detecção da p53 por imuno-histoquímica, entre eles, quantidade do antígeno, afinidade com o anticorpo, concentração deste, duração das encubações, sensibilidade do sistema de detecção e fixação ${ }^{19}$. Além disso, existem três fenômenos principais responsáveis em alguns casos por detecção da p53 por imuno-histoquímica, sem que haja alterações no gene p53 ou no cromossomo 17. O primeiro deles diz respeito a imuno-histoquímica para detecção da p53 ter alta sensibilidade, mas nem tanta especifidade porque células positivas para p53 não estão mutadas em $10 \%$ a $29 \%$ dos casos quando analisadas por outras técnicas que estudam a mutação gênica ou deleção cromossômica específica ${ }^{20}$. Essa discordância pode ser devido à estabilização da p53 selvagem por mecanismos ainda não elucidados. Postula-se que lesão celular, resposta fisiológica à lesão no DNA, proliferação celular desre gulada ou outros mecanismos que alterem a fisiologia da célula podem prolongar a meia-vida da prote ína p53 selvagem, a qual irá se evidenciar positivamente na imunohistoquímica, mesmo sem estar mutada ${ }^{19-22}$. Em segundo lugar, a acumulação da proteína não mutante nas células neoplásicas pode ser devido à sua estabilização e inativação pelo produto do gene MDM2, principalmente quando este se encontra amplificado, formando o complexo MD $\mathrm{M} 2 / \mathrm{p} 53$, o qual não é degradado pela enzima específica que degrada a $p 53^{19}$. O último fenômeno é a estabilização da p53 selvagem mediante form ação de complexos com proteínas virais ${ }^{19}$. Neste caso, a meia-vida da proteína selvagem também aumenta, sendo detectada pela imuno-histoquímica, mesmo não estando mutada.

Cabe ressaltar, finalmente, que além da via p53 existem outras vias genéticas na tumorigênese das neoplasias astrocitárias ${ }^{14,22}$ e que a expressão da p53 pode ser diferente em diferentes populações, dependendo da área geográfica estudada ${ }^{22}$. Quanto ao primeiro argumento, existem GBMs que, além de terem comportamento mais agressivo, não têm origem de glioma de menor grau de malignidade, sendo denominados glioblastomas primários. Do ponto de vista genético, estão associados à alta taxa de mutação do receptor de fator de crescimento epidérmico (EGFR), deleções no gene p16 e mutações do gene PTEN ${ }^{1,2}$, apresentando mutações no p53 em somente $10 \%$ dos $\operatorname{casos}^{4,21}$. Este fato pode corroborar a maior prevalência de GBMs sem proteína p53 mutada nesta amostra.

Um aspecto essencial a ser discutido é o conceito de que a expressão da p53 pode ser diferente em diferentes populações, dependendo da área geográfica estudada, o que acontece por existirem diversos fatores mutagênicos ambientais em variadas regiões do mundo ${ }^{22,23}$. Com base nesta definição, Das et al. ${ }^{24}$ realizaram estudo genético na população asiática com GBM porque a incidência desta neoplasia na população de Cingapura era de somente $25 \%$ das neoplasias primárias do SNC, sendo menor que a porcentagem de $40-60 \%$ relatada na litera- 
tura mundial. Nesse estudo, em que foram analisados o EGFR, MDM-2, PDGRF-ALFA, proteína p53 e o gene TP53 em 39 pacientes asiáticos porta dores de GBM, os resultados sugeriram que ambas as vias genéticas (tanto do GBM primário quanto do secundário) estavam presentes na maioria dos tumores, sugerindo que os modelos de carcinogênese do GBM diferem na população asiática. Além disso, foram evidenciadas três mutações no gene p53 ainda não relatadas no GBM.

Dentre os tumores imunomarcados que demonstraram alta quantificação de marcação (3+ ou $4+)$, todos os casos foram grau IV. Esses achados são corroborados por outros estudos ${ }^{16-18}$.

$\mathrm{Na}$ análise estatística que comparou Ki-67 com p53, não houve correlação entre estas variáveis. Dois estudos corroboram estes resultados ${ }^{25,26}$, enquanto dois os contestam ${ }^{27,28}$. Primeiramente, Kordek at al. ${ }^{25}$ compararam a expressão da proteína p53 com Ki-67 e PCNA em nove astrocitomas pilocíticos, 12 astrocitomas grau II, nove grau III e 30 grau IV. Em relação à proteína $\mathrm{p} 53$ foram imunomarcados, respectivamente, $0 \%, 41,7 \%, 33,3 \%$ e $53,3 \%$. Estas porcentagens foram confrontadas estatisticamente com Ki-67 e PCNA, não havendo significância estatística. Outro artigo que não encontrou correlação e, dessa forma, concordou com os resultados deste estudo foi o de Cunningham et al. ${ }^{26}$, que estudaram a expressão das proteínas p53, MIB-1 e PCNA em 105 astrocitomas e 15 oligoastrocitomas. Em relação a 102 pacientes, $85 \%$ evidenciaram imunomarcação para p53, não havendo associação com idade, sexo ou grau tumoral. De 104 pacientes, $87 \%$ apresentaram marcação pelo MIB-1 e sua intensidade foi proporcional ao grau histológico. Entretanto, quando foram correlacionadas estatisticamente as d i f e rentes variáveis imuno-histoquímicas, o coeficiente de correlação foi próximo de zero. Por outro lado, Sarkar et al. ${ }^{27}$, analisando a perda da heterozigose (LOH) do cromossomo 17, o gene p53, a proteína p53 e o MIB-1 em neoplasias astrocitárias de alto e baixo grau encontraram forte associação entre LOH do cromossomo 17 e proteína p53 mutada com MIB-1. Não houve associação, entretanto, estatisticamente significativa entre MIB-1 e mutação do gene p53. Jaros et al. ${ }^{29}$, estudando 43 astrocitomas, acharam correlação entre Ki-67 e p53 com significância estatística.

Existem estudos que correlacionaram idade com p53 mutada ${ }^{18}$. Estudos de astrocitomas em pacientes pediátricos, entretanto, encontraram menos p53 mutada em relação aos adultos ${ }^{30}$. Todavia, estudos subseqüentes ${ }^{31,32}$ não concordaram com estes achados. Recentemente, Pollack et al. ${ }^{33}$, estudando astrocitomas de alto grau de malignidade, encontraram mutação da p53 em somente 11,8\% das crianças com idade abaixo de três anos, enquanto nos pacientes acima dessa idade, a porcentagem foi $40 \%$, com diferença estatisticamente significativa, evidenciando que a patogênese desse câncer nas crianças de mais idade é semelhante à dos adultos, enquanto que nas crianças menores de três anos, outra via molecular, provavelmente, é utilizada para o desenvolvimento tumoral.

Embora a idade seja um importante fator prognóstico quando analisada isoladamente na sobrevida de pacientes port a d o res de neoplasias astrocitárias, independentemente da relação entre as vias de carcinogênese dependentes e independentes da p53 descritas, a proteína Ki-67 não tem sido estudada sistematicamente em relação a este fator, tampouco ao sexo. Isto se deve, provavelmente, a observações iniciais e ao fato de não haver hipótese biológica que corrobore o substrato teórico necessário para o desenvolvimento de estudos mais específicos relativos a este tema. No que tange a p53, em relação ao sexo, não houve nesta casuística diferença estatisticamente significativa entre estas variáveis. Estes achados são semelhantes a observações de vários autore $s^{4,8,16,17}$, as quais não demonstraram qualquer relação entre sexo e p53.

Em conclusão: Ki-67 correlacionou-se com maior grau de malignidade, sendo estatisticamente significativo. p53 correlacionou-se com maior grau de malignidade, com exceção das neoplasias de grau III, sem significância estatística. Ki-67 e p53 não a p re sentaram correlação estatisticamente significativa. Ki-67 e p53 não apresentaram correlação estatisticamente significante com idade e sexo.

\section{REFERÊNCIAS}

1. De Angelis LM. Brain tumor. N Engl J Med 2001;344:114-123.

2. Shiraishi S. Influence of p53 mutations on prognosis of patients with glioblastoma. Cancer 2002;95:249-257.

3. Yonish-rouach E. A question of lie or death: the p53 tumor suppressor gene. Pathol Biol 1997;45:815-823.

4. Kleihues P, Cavenee WK. Pathology and genetics of tumours of the nervous system: World Health Organization classification of tumors. Lyon: LARC Press, 2000.

5. Baserga R. Oncogene and the strategy of growth. Cell 1994;79:927-939.

6. Korshunov A, Golanov A, Sycheva R. Immunohistochemical markers for prognosis of anaplastic astrocytomas. J Neurooncol 2002;58:203-215.

7. Kurtkaia-yapicier Ö, Scheithauer BW, Hebrink D, James CD. p53 in nonneoplastic central nervous system lesions: an immunohistochemical and genetic sequencing study. Neurosurgery 2002;51:1246-1255.

8. Scholzen T, Gerdes J. The Ki-67 protein: from the known and the unknown. J. Cell Physiol 2000;182:311-322.

9. Matsumoto T, Fujii T, Yabe M, Oka K, Hoshi T, Sato K. MIB-1 and p53 immunocytochemistry for diff e rentiating pilocytic astrocytomas and astrocytomas from anaplastic astrocytomas and glioblastomas in children and young adults. Histopathology 1998;33:446-452. 
10. McKeever PE, Straw derman MS, Yamini B, Mikhail AA, Blaivas M. MIB-1 proliferation index predicts survival among with grau II astrocytoma. J Neuropathol Exp Neurol 1998;57:931-936.

11. Hara A, Saegusa M, Mikami T, Okayasu I. Loss of DCC expression in as troytomas: relation to p53 abnormalities, cell kinetics, and survival. J Clin Pathol 2001;54:860-865.

12. Kayaselcuk F, Zorludemir S, Gumurduhu D, Zeren H, Erman T. PCNA and Ki-67 in central nervous system tumors: correlation with the histological type and grau. J. Neurooncol 2002;57:115-121.

13. Fults D, Brockmeyer D, Tullous MW, Pedone CA, Cawthon RM. p53 mutation and loss of heterozygosity on chromosome 17 and 10 during human astrocytic progression. Cancer Res 1992;42:674-679.

14. Sidransky D. Mikkelsen T, Schwechheimer K, Rosenblum ML, Cavanee $\mathrm{W}$, Volgestein B. Clonal expansion of p53 cells is associated with brain tumor progression. Nature 1992;355:846-847.

15. Louis DN, Cavenee WK. Molecular biology of central nervous system tumors. Disponível em:<http: / / brain.mgh.harvard.edu / moleculargenetics.htm> Acesso em: 01 mar. 2003.

16. Barbareschi M, Luzzolino P, Pennella A. p53 protein expression in central nervous system neoplasms. J Clin Pathol 1992;45:583-586.

17. Ellison DW, Gatter KC, Steart PV, Lane DP, Weller RO. Expression of the p53 protein in a spectrum of astrocytic tumors. J Pathol 1992;168:383-386.

18. Vital A, Loiseau H, Kantor G, et al. p53 protein expression in grau II astrocytomas: immunohistochemical study of 100 cases with long-term follow-up. Pathol Res Pract 1998;194:831-836.

19. Hall PA, Lane DP. p53 in tumor pathology: can we trust immunohistochemistry? Revisited. J Pathol 1994;172:1-4.

20. Litofsky NS, Recht LD. The impact of p53 tumor suppressor gene on glioma biology. Neurosurg Focus 1997;3:3.

21. Watanabe K, Sato K, Biernat W, et al. Incidence and timing of p53 mutations during astrocytoma prog ression in patient with multiple biopsies. Clin Cancer Res 1997;3:523-530.

22. Shields PG, Harris CC. Molecular epidemiology and the genetics of environmental cancer. JAMA 1991;266:681-687.
23. Darnton E. Demystified...p53. Mol Pathol 1998;51:248-253.

24. Das A, Tan WL, Teo J, Smith DR. Glioblastoma multiforme in an Asian population: evidence for distinct genetic pathway. J Neurooncol 2002; 60:117-125.

25. Ko rdek R, Biernat W, Debiec-Rychter, Alwasiak J, Liberski PP. Comparative evalution of p53-protein expression and the PCNA and Ki-67 proliferating cell indices in human astrocytomas. Pathol Res Pract 1996; 192:205-209.

26. Cunningham JM, Kimmel DW, Scheithauer BW, O'Fallon JR, Novotny PJ, Jenkins RB. Analysis of proliferation and p53 expression in gliomas of astrocytic orign: relationships and prognostic value. J Neurosurg 1997;86:21-30.

27. Sarkar C, Chattopadhyay P, Ralte AM, Mahapatra AK, Sinha S. Loss of heterozygosity of a locus in the chromossomal region $17 \mathrm{p} 13.3$ is associated with increased cell proliferation in astrocytic tumors. Cancer Genet Cytogenet 2003;144:56-64.

28. Litofsky NS, Hinton D, Raffel C. The lack of a role p53 in astrocytomas in pediatric patients. Neurosurgery 1994;34:967-973.

29. Jaros E, Perry RH, Adam L, et al. Prognostic implications of p53 protein, ephidermal growth factor receptor, and Ki-67 labelling in brain tumors. Br J Cancer 1992;66:373-385.

30. Schiffer D, Chio A, Giordana MT, Leone M, Soffietti R. Prognostic value of histologic factors in adult cerebral astrocytoma. Cancer 1988;61:386-393.

31. Lang FF, Miller DC, Pisharody S, Koslow M, Newcomb EW. High frequency of p53 protein accumulation without gene mutation in human juvenile pilocytic, low grau and anaplastic astrocytomas. Oncogene 1994;9:949-954.

32. Pollack IF, Hamilton RL, Finkelstein SD, et al. The relationship between TP53 mutation and overexpression of p53 and prognosis in malignant gliomas of childhood. Cancer Res 1997;57:304-309.

33. Pollack IF, Finkelstein SD, Burnham J, et al. Age and TP53 mutation $\mathrm{f}$ requency in childhood malignant gliomas: results in a multi-institutional cohort. Cancer Res 2001;61:7404-7407. 